\title{
Economic Freedom and Economic Growth in South Africa
}

\author{
Clive E. Coetzee \\ North-West University, South Africa \\ clive.coetzee@kzntreasury.gov.za \\ Ewert P. J. Kleynhans \\ North-West University, South Africa \\ 1128957o@nwu.ac.za
}

\begin{abstract}
The economic growth and economic freedom nexus is studied in this article and applied to South Africa in an empirical study. Economic freedom is founded on the free or private market economy, based on competition, where voluntary exchange occurs and a legislative framework ensures the safety of market agents and private property. As part of the literature study, the Index of Economic Freedom, the Economic Freedom of the World Index and the Freedom in the World Index were studied and applied to South Africa. An empirical analysis was conducted, cross-correlation functions were estimated, and Granger causality functions, regression analysis and finally a vector auto-regression model (VAR) were constructed and estimated. The research findings from South Africa support the literature, suggesting that there are indeed some indications that greater levels of economic freedom support higher rates of economic growth in a country.
\end{abstract}

Key Words: economic freedom, privilege, regulation, monopoly, economic growth

JEL Classification: L12, H1, P5, D72, O4O

https://doi.org/10.26493/1854-6935.15.169-185

\section{Introduction}

The economic freedom and growth nexus has been studied and debated by economists since the seminal work of Adam Smith An Inquiry into the Nature and Causes of the Wealth of Nations, published in 1776 (1986). Generally, it has been contended and debated that free economies will be more productive and innovative. Economic freedom is considered the ultimate incentive for the optimal utilisation of scarce resources, by developing a favourable economic and political environment for sound competitiveness and incentivising, and empowering human creativity and innovation. A free private market bestows upon individuals the freedom of choice in terms of what to produce, to consume and to give. The invisible 
hand incentivises and empowers individuals to follow their own interests and cooperate with others on a non-coercive (voluntary) basis (quoted in Gwartney and Lawson 2002).

The large disparities in the economic performance and level of progress between countries are widely accepted and acknowledged. With this in mind, there seems to be a comprehensive body of literature that identifies a number of factors that, as a collective, illustrate why some countries' employment and income growth experiences or records are better than others are. Economies differ with regard to their level of technological development, focus of competitive advantage, development funding from abroad, the stock of human capital, and the levels of political corruption and uncertainty. Recent literature explores the contribution of institutions to economic development. There is evidence suggesting that where levels of economic freedom are higher, countries enjoy increasing economic growth and development.

A country's levels of prosperity and progress depend on its measure of freedom in its economic endeavours (Gwartney and Lawson 2002). The authors found that economic freedom generates economic prosperity, which raise the income of everyone, especially the poor. Dutz and Hayri (2000) therefore also found a mutually inclusive long-run relationship between a country's competitive policies and its economic development. The results suggest that key measures related to intensity of economic wide competition are positively associated with unexplained growth. The relationship between economic freedom and how it affects a county's economic growth is investigated in this paper given the seemingly wide spread view that economic freedom supports and 'incentivise' economic growth. This view is based on a sound theoretical foundation and draws on research done on economic freedom and growth, as reported in existing academic literature.

Such a possible connection and relationship will be tested empirically within the South African (s A) context employing regression and vector auto regression methodologies after a clear explanation of the data, data sources, and the time period of the data, study methodology and hypotheses. The empirical findings tentatively support the hypothesis suggesting that economic freedom is indeed an important variable in the s A growth context for example the results also indicate that economic growth is affected by the lagged period 1 and period 2 of economic freedom using the Freedom in the World measure of Freedom House (see https://freedomhouse.org). 


\section{A Conceptual Framework}

Nobel laureate, Fredrick von Hayek, developed and conceptualised his notion of freedom (economic freedom) in 'The Constitution of Liberty'. Hayek (1960) posited that a proper legislative framework forms a primary element that ensures the freedom of economic agents. The concept of economic freedom refers to individual role-players and their behaviour, implying methodological individualism. Hayek (1960) further stated that economic freedom should be understood not as the absence of government behaviour, but as freedom under or within governmental law. Economic freedom is, therefore, a relative term in the relevant economic environment.

Hayek (1960) stated that the use of force (coercion) is an important concept to the understanding of economic freedom and that governmental behaviour can be classified between coercive and non-coercive behaviour. Hayek (1960) further stated that some measure of enforcement is to the advantage of economic role-players. Appropriate coercive behaviour is that which is consistent with economic freedom and, therefore, by definition, does not hurt economic freedom. Hayek (1960) does, however, warn that government has the power of enforcement and to that extent is therefore the greatest danger to freedom in the market place. The only acceptable means of government coercion is by enforcing rules. It is the therefore the type rather than the size or quantity of government behaviour that is of relevance to the concept of economic freedom. The focus should therefore rather be on the possible coercive and not on the non-coercive government activities (Kapás and Czeglédi 2007).

The meaning of freedom should, however, be more narrow or specific (Barzel 2000). In most cases, it is defined as the absence or lack of force, i.e. coercion, except for government force, to impose rules that are known and accepted, such as the protection of individuals from public or private coercion. With the monopoly governments have over power, they are able to manipulate people's economic and entrepreneurial behaviour. The legislative power of government allows people to realise their own economic objectives, free of any unnecessary interference or confiscation by others. This allows people to develop their productive capacity and create their own wealth in the manner they regard as optimal. If government ownership of force goes beyond these absolutes, economic freedom is negatively affected (Hayek 1960). Government force and specifically the manner in which it exercises its monopoly power must therefore be con- 
tained and limited through the implementation of normative constraints.

Kapás and Czeglédi (2007) argue that the legal principle that law should govern provides a criterion against which freedom can be evaluated. This ideal of freedom is best portrayed as reconciliation between governmental force and free economic behaviour, where the rules of the game are openly known to all (Bastiat 1850; Hayek 1960; Kapás and Czeglédi 2007). In other words, the legal principle that law should govern is a doctrine or blueprint of the ideal situation. Hayek (1960) states: 'The rule of law is therefore not a rule of the law per se, but rather a rule concerning what the law ought or should to be, a meta-legal doctrine or a political ideal.' The legal principle that law should govern limits or constrains government in its coercive behaviour and is critical to ensure freedom. Individual liberty and the rule of law are therefore synonymous (Voigt 1998).

Kapás and Czeglédi (2007) integrated economic freedom as part of economic growth and entrepreneurial theory in a logical manner. They realised that innovation and free market participation enable people to reach their objectives in the market place. Holcombe (1998; 2003a; 2003b) highlights the process by which entrepreneurship leads to and supports economic growth. This view is supported by several empirical studies, such as the work of Ovaska and Sobel (2005) and Kreft and Sobel (2005).

There exists a link between economic growth and innovation because entrepreneurial behaviour creates undiscovered profit opportunities for other entrepreneurs. The bottom line is that entrepreneurial activity develops opportunities for other entrepreneurs (Holcombe 1998; 2003a; 2003b). The concept of economic freedom therefore underlies and supports economic growth.

\section{Does Economic Freedom Matter? A Literature Review}

The extent to which economic freedom leads to economic progress was researched by Panahi, Assadzadeh and Refaei (2014). They investigated the economic freedom and economic growth connection using data from a selection of 13 Middle Eastern and North African (MENA) countries from 2000 to 2009. The study makes use of two models: firstly, they estimated a model that determines an index that shows the total level of economic freedom, which utilised a number of control variables (variables that stay constant) that would not be affected by national growth; and secondly, the freedom index was divided into sub-categories that constituted the index. 
The standard control variables include government and investment share of GDP, population growth and primary school enrolment per country. The random (RE) and fixed (FE) effects models were estimated, taking the panel characteristics of the dataset into account. The fixed effect model was found to be superior to the random effect model in all the estimates. Irrespective of the model used, the study revealed a significant positive association between economic freedom and the economic growth rate a country experiences.

Wulandari (2015) studied the economic freedom and economic growth connection of Indonesia over the period 2004 to 2014. The study used a positivist approach because of the need to test the data quantitatively. The vector auto-regression (VAR) model applied follows the research conducted by Lee (1992). The VAR estimation indicated a positive relationship between economic freedom and a country's economic growth rate and vice versa. This supports previous studies that stated that economic freedom leads to growth. Wulandari (2015) suggests that, in a country that is concerned with economic growth and social welfare, market liberalisation is a necessary institutional reform.

Justesen (2006) used panel data from 1970 to 2000 of several countries and utilised Granger causality tests to determine to what extend the variation in economic freedom as a whole, as well as its sub-divisions, can explain the variation in the economic growth rate of these countries.

Justesen concluded that the relationship between economic freedom and growth is much more complex than usually assumed. The connection between these variables does exist, as does the relationships with the sub-divisions of freedom. Taking the latter into regard was found to be very important. The study found that, in general, overall economic freedom seems to cause economic growth, both with regard to the level and the rate of change. The causality appears to run both ways between the growth and freedom variables. Their research results suggested that property rights might have a causal effect on growth. Changes in property rights, on the other hand, seem to not Granger-cause economic growth. The sub-division variables on labour, credit and regulation of business were the only part of economic freedom that wielded a definite unidirectional Granger-causal effect on economic growth, irrespective of the model specification (Justesen 2006).

The connection between economic freedom and the growth in state employment in America (USA) was investigated by Garrett and Rhine (2010). They found that besides the clear-cut factors that determine 
growth, such as human capital and economic industrial diversity, economic freedom is a major cause of growth. They did, however, find that this relationship does fluctuate with regard to the period under review.

The relationships between the advancement of economic freedom and changes in national production and income per capita were studied by Gurgul and Lach (2011). They studied countries in the European Union $(\mathrm{EU})$ that underwent transition between the years 2000 and 2009 and the connection between rising economic freedom and income growth and development are positive, both on theoretical and empirical grounds. They applied the Granger and Huang (1997) method of evaluating panel datasets. They focused on the forecasting abilities of the models instead of significance tests.

Gurgul and Lach (2011) tested for Granger causality using two forecastbased methods. They estimated out-of-sample forecasts to determine any difference between the augmented model and the restricted models. They confirmed that, in all the countries investigated, economic freedom Granger caused higher economic growth, particularly when utilising the Fraser overall index. Gurgul and Lach (2011) state that the results of the causality analysis provide a solid basis to assert that the higher a country's level of economic freedom, the better the prospects of growth. This is especially the case in less developed $\mathrm{EU}$ economies.

The connection between economic freedom in the SADC region and the economic growth in those countries were studied by Gorlach and Le Roux (2013), both on an aggregate and individual component basis. The empirical research of Gorlach and Le Roux (2013) confirmed the link between economic freedom in SADC countries (Southern Africa Development Community) and their per capita GDP growth. They established a positive relationship and also confirmed that economic freedom Granger causes economic growth; therefore, increasing levels of economic freedom implies a higher creation of wealth in SADC countries.

Based on the Granger-causality test using the individual components, the significant connections on a $1 \%$ level of significance were free international trade, which caused better legislation of business, property rights, labour and credit, with some feedback effect. Mutual causes were established between the size of government and its ability to secure loans, while international free trade also Granger-causes better regulations, at a significance level of 5\% (Gorlach and Le Roux 2013).

Regions with a higher degree of economic freedom receive more foreign direct investment, which enhance their economic progress (Ajide 
and Eregha 2015). It was also found that indices of economic freedom measures are positively related to constant and stochastic factors. A 10\% rise in economic freedom raises national income and production by $5.7 \%$. This emphasises the economic freedom as a determinant supporting economic progress and development.

\section{South Africa's Ranking with regard to Economic Freedom}

The three most comprehensive studies on the measure economic freedom are the Heritage Foundation's Index of Economic Freedom (http://www .heritage.org), the Fraser Institute's Economic Freedom of the World Index (https://www.fraserinstitute.org), and the Freedom in the World Index published by Freedom House (Puddington and Roylance 2016).

The Heritage Foundation publishes an Index of Economic Freedom (IEF) of 186 countries on an annual basis in collaboration with the Wall Street Journal. The Index of Economic Freedom of the Heritage Foundation uses ten qualitative and quantitative factors, which includes the legislative framework that protects private ownership, and opposes corruption. It considers the size of government expenditure and the efficiency to regulate exchange labour freedoms, as well as the accessibility to markets, funds and financial freedom of a country.

The Index of Economic Freedom ranks countries between no freedom at $\mathrm{o}$ and 100 at total freedom. On this index, South Africa's level of economic freedom has risen from a score of approximately 60 in 1994 to approximately 62 during 2016 . This score rose to some extent by the turn of the millennium to approximately 64, but declined again by 2016 to where it originally was. The Index of Economic Freedom ranks South Africa currently in 8oth place, out of 186 countries in 2016. South Africa is ranked as 'moderately free.' South Africa is ranked 6th in Sub-Saharan Africa (46 countries). The trend suggests a steady regression of economic freedom, especially post-2005.

Countries and regions that enjoy the most economic freedom in order of merit are Switzerland, the United Kingdom, Canada, Ireland, New Zealand, Singapore, the United Arab Emirates, Chile, Jordan, and Hong Kong, Mauritius (see https://www.fraserinstitute.org). During 2000 the United States was second, but now only ranks 16th in the world. Countries with the worst economic freedom record are Angola, Zimbabwe, Algeria, the Central African Republic, Chad, Republic of Congo, Syria, Libya, Venezuela and Argentina.

The Economic Freedom of the World (E FW) report is published by the 
Fraser Institute (https://www.fraserinstitute.org). They also define economic freedom as people's right to act in the market place without intervention by the authorities. The Economic Freedom of the World Index (E FW) of the Fraser Institute includes 21 components. It utilises a varied set of objective variables that regard the size of government, openness and freedom to international trade, availability of credit and funds, as well as capital market regulations. It also considers the legislative framework that guarantees the ownership of private property, and regulates the supply of credit, human resources and free exchange. Unfortunately, it excludes some important variables because of data constraints and measurement issues (Gwartney and Lawson 2002).

The Fraser Institute scores countries between o and 10 with o the least free and 10 representing the freest (E FW). The Economic Freedom of the World measure of the Fraser Institute ranked South Africa 96th out of 175 countries on government size, receiving the lowest ranking of 121, while the legal system and property rights received the highest ranking of 61 out of 175 . South Africa's rating experienced a progressive regression since 2005. The rankings of some other major countries are: the United States (16th), Germany (3oth), Japan (4oth), South Korea (42nd), France (57th), Italy (69th), Mexico (88th), Russia (102nd), India (112th), China (113th) and Brazil (124th).

Freedom House acknowledges South Africa's freedom status according to their Freedom in the World Index (FWI), but also indicates regression since 2005 (Puddington and Roylance 2016). The Freedom House scores countries between 1 and 7 with 1 representing the freest and 7 the least free (FW). South Africa (during 2016) is classified as 'free' with an aggregate score of 79 where a larger score indicates a greater level of freedom. This compares to Brazil, Russia, China and India at 81, 22, 16 and 77, respectively.

\section{Data Used}

The study makes use of a secondary dataset that contains annual data on South Africa's real economic growth rate (GI) from 1995 to 2016. The South African Reserve Bank's (s A R B) economic growth estimate for 2016 was used, whereas the data from 1995 to 2015 was obtained from Statistics South Africa. Economic freedom data for South Africa (for the same period) was collected from the Heritage Foundation, Fraser Institute and the Freedom House.

Both the Heritage Foundation and the Frasier Institute's economic 
freedom scores increase from o to 100 and o to 10, while the Freedom House economic freedom scores decrease from o to 7 .

In this study, two models are used, i.e. a multivariate ordinary least square (OLS) regression model and a vector autoregressive regression (VAR) model. The VAR is included to control for the possible endogeneity of the variables that is especially important when doing time series analysis involving causal processes.

The multivariate oLs regression model includes two control variables, i.e. the annual percentage change of per capita gross national income $\left(y_{i}\right)$ and the annual change of gross fixed capital formation $\left(\mathrm{NV}_{i}\right)$. Both datasets were obtained from the SARB. The inclusion of the control variables are in line with the study by Panahi, Assadzadeh and Refaei (2014). The primary reason to include control variables is to exclude alternative explanations while testing the hypotheses with the explanatory variables.

The relationship between Economic Freedom and Economic Growth in South Africa was investigated in the current study, which tested the hypothesis that a statistically significant association exists between economic freedom in South Africa and economic growth.

\section{Empirical Analysis: Economic Freedom and Economic Growth Nexus in South Africa}

An empirical analysis of the data was applied to South Africa by the authors and we report our research results in this section. The descriptive statistics of the country's total income and production (GDP), the Index of Economic Freedom (IEF), Economic Freedom of the World Index (EFW) and the Freedom in the World Index (FWI), in relation to South Africa, are presented in table 1 . The statistics suggest that these variables are normally distributed $(p>0.05)$, with the exception of the IEF and EFW. Non-normality may increase the chance of a false positive result when using a test that assumes normality. However the model makes no assumptions about normality and therefore these is no need for the independent variables to be normally distributed. None the less, the effect of the variations of the independent variables is important to investigate to determine the major outliers or concentrated values.

The analysis found economic freedom started decreasing post-2005 and this is also evident when applying the polynomial (2nd order) function and a three-period moving average function.

Stationarity of the variables were assessed using the Augmented Dickey- 
TA B LE 1 Descriptive Statistics of the Indicators

\begin{tabular}{lrrrr}
\hline Item & GDP & IEF & EFW & FW I \\
\hline Mean & 2.87 & 63.33 & 6.89 & 1.73 \\
Median & 2.95 & 63.25 & 6.90 & 1.50 \\
Maximum & 5.60 & 67.10 & 7.85 & 2.00 \\
Minimum & -1.50 & 60.70 & 6.30 & 1.50 \\
Std. Dev. & 1.72 & 1.37 & 0.36 & 0.25 \\
Skewness & -0.49 & 1.03 & 1.14 & 0.18 \\
Kurtosis & 3.27 & 4.77 & 4.44 & 1.03 \\
Jarque-Bera & 0.94 & 6.72 & 6.62 & 3.67 \\
Probability & 0.62 & 0.03 & 0.04 & 0.16 \\
Sum Sq. Dev. & 62.02 & 39.66 & 2.73 & 1.36 \\
\hline Observations & 22 & 22 & 22 & 22 \\
\hline
\end{tabular}

notes Authors' own analysis using data from Statistics South Africa, the Heritage Foundation, Fraser Institute and the Freedom House.

TABLE 2 Economic Freedom vs. Economic Growth

\begin{tabular}{lcccc}
\hline Period & GDP & IEF & EFW & FW I \\
\hline Average: 1995 to 2004 & 3.10 & 63.89 & 7.03 & 1.60 \\
Average: 2005 to 2016 & 2.68 & 62.86 & 6.84 & 1.90 \\
\hline
\end{tabular}

notes Authors' own analysis using data from Statistics South Africa, the Heritage Foundation, Fraser Institute and the Freedom House.

Fuller test as a unit root test. The results revealed that the GDP variable and the three economic freedom variables are indeed non-stationary in the level form and integrated in order 1. This suggests the presence of a structural break in each of the three economic freedom variables, indicating an unexpected shift estimated around 2005 (the complete results of stationarity analysis are available upon request).

Table 2 displays the average annual economic growth rate for the periods 1995 to 2004 and 2005 to 2016 . The results suggest that the economy performed better during the period of relative economic freedom (1995 to 2004) vis-à-vis the period of decreasing economic freedom (2005 to 2016).

A statistical analysis using cross-correlation functions (variables integrated in order 1) was then conducted. Cross-correlation is a measure of the similarity of two series as a function of the lag of one variable relative to the other variable. Table 3 suggests a lagged correlation and delayed 
TABLE 3 Cross-Correlation Results (integrated in order 1)

\begin{tabular}{lrrrrrr}
\hline Lag & IEF(-1) & IEF $(+1)$ & EFW $(-1)$ & EFW $(+1)$ & FWI $(-1)$ & FWI $(+1)$ \\
\hline 1 & -0.3107 & -0.3107 & 0.0788 & 0.0788 & -0.0115 & -0.0115 \\
2 & 0.0400 & 0.0952 & 0.353 & -0.2542 & -0.2461 & 0.0479 \\
3 & 0.0913 & 0.0680 & -0.2232 & -0.1602 & -0.558 & 0.0952 \\
4 & 0.1227 & -0.0664 & 0.1505 & 0.2951 & 0.5443 & 0.2128 \\
5 & 0.5595 & 0.3814 & -0.0331 & -0.1603 & 0.0353 & -0.0892 \\
6 & -0.4618 & -0.3582 & 0.1688 & -0.0479 & -0.099 & 0.1235 \\
7 & -0.3596 & -0.3265 & -0.331 & -0.0398 & 0.014 & -0.1774 \\
\hline
\end{tabular}

NOTES Authors' own analysis using data from Statistics South Africa, the Heritage Foundation, Fraser Institute and the Freedom House.

response between the economic freedom of a region and its economic growth of approximately two to five years. There did, however, seem to be no or very little lagged correlation between a country or region's rate of growth in the economy and economic freedom.

The second statistical analysis applied is the Granger causality function (null hypothesis = no Granger causality). This function examines whether one variable leads to variation in another and to what extent its present values can be explained by historical data of the two variables, and then determines whether a time lag in the independent variable could enhance the accuracy of the estimation. An independent variable Grangercaused another variable if it can enhance its ability to forecast accurately. This will be the case if the regression results indicate that by lagging a variable, it improves the forecast and the coefficients are statistically significant.

The estimated results of the Granger causality tests, with the variables integrated in order 1, are displayed in table 4 . The estimated figures in the table suggest that economic freedom can Granger-cause the economic growth rate of a country and not the other way around.

Thirdly, the effect of economic freedom on economic growth was analysed using the three measures of overall economic freedom using regression analysis:

$$
g_{i}=\alpha+\beta_{1} y_{i}+\beta_{2} \mathrm{INV}_{i}+\delta \mathrm{EF}_{i}+\varepsilon_{i},
$$

where $g_{i}$ is annual economic growth rate (percentage), $y_{i}$ is the annual percentage change of gross national income per capita, and $\mathrm{INV}_{i}$ is the annual percentage change in gross fixed capital formation. These variables are often significant in growth and are almost standard in this type 
TABLE 4 Pairwise Granger Causality Results (integrated in order 1)

\begin{tabular}{lrl}
\hline$d$ (variable) 4 lags & $F$-statistic & Prob. \\
\hline IEF does not Granger-cause GDP & 8.66 & $0.005^{*}$ \\
GDPpc does not Granger-cause IEF & 0.69 & 0.620 \\
EFW does not Granger-cause GDP & 0.63 & 0.650 \\
GDPpc does not Granger-cause EFW & 0.59 & 0.680 \\
FWI does not Granger-cause GDP & 7.07 & $0.009^{*}$ \\
GDP does not Granger-cause FW I & 0.33 & 0.850 \\
\hline
\end{tabular}

Notes Authors' own analysis using data from Statistics South Africa, the Heritage Foundation, Fraser Institute and the Freedom House.

TABLE 5 Regression Result Estimations Using the Three Indicators of Economic Freedom: GDP Growth (integrated in order 1)

\begin{tabular}{|c|c|c|c|c|c|c|}
\hline \multirow[t]{2}{*}{$d($ variable $)$} & \multicolumn{2}{|c|}{ IEF } & \multicolumn{2}{|c|}{ EFW } & \multicolumn{2}{|c|}{ FWI } \\
\hline & $\mathrm{C}$ & $p$ & $\mathrm{C}$ & $p$ & C & $p$ \\
\hline $\mathrm{Y}$ & $0.70^{*}$ & 0.00 & $0.76^{*}$ & 0.00 & $0.84^{*}$ & 0.00 \\
\hline INV & $0.07^{*}$ & 0.04 & $0.08^{*}$ & 0.02 & 0.05 & 0.14 \\
\hline $\mathrm{EF}$ & -0.33 & 0.07 & $1.27^{*}$ & 0.03 & 1.49 & 0.14 \\
\hline Constant & 0.01 & 0.99 & -0.02 & 0.91 & 0.00 & 1.00 \\
\hline$R^{2}$ & 0.78 & & 0.80 & & 0.78 & \\
\hline$F$-statistic & $22.63^{*}$ & 0.00 & $25.46^{\star}$ & 0.00 & $20.64^{*}$ & 0.00 \\
\hline Sum squared residuals & 12.95 & & 11.78 & & 13.96 & \\
\hline
\end{tabular}

NOTES C - coefficient, $p-p$-value. ${ }^{*}$ Statistically significant. Authors' own analysis using data from Statistics South Africa, the Heritage Foundation, Fraser Institute and the Freedom House.

of model, according to Carlson and Lundström (2002). $\mathrm{EF}_{i}$ is the economic freedom index values for the period 1995 to 2016. The stochastic error term is $\varepsilon$. Since the variables are non-stationary in level form, the 1st difference values (order I(1)) were used, i.e. $d\left(g_{i}\right)$ etc.

The results of the regression estimation are indicated in table 5. They suggest that income per capita and investment are highly significant. Economic freedom is only found to be significant when figures from the Economic Freedom of the World Index of the Fraser Institute are used.

Sometimes, the process of estimation and inference becomes more complicated because of the presence of endogenous variables on both sides of the equation, implying variable endogeneity in both the dependent and independent variables. When the results of the regression anal- 
ysis are studied, it may be suggested that economic freedom may be endogenous to economic growth, making ordinary least square (OLS) an inappropriate estimator. The results of the Granger causality tests (table 5) suggest that economic freedom consistently predetermines the growth rate of an economy. Economic freedom could, however, be endogenous, making the statistical findings on economic growth and economic freedom spurious.

A vector auto-regression model (VAR) was then estimated, based on a simple bivariate function and displayed below. Sims (1980) was the first to propose a VAR model, since there is no need to be concerned about endogeneity and exogenous variables, as all variables are considered as endogenous variables. The time path of the $\{g t\}$ is dependent on realisations of the economic freedom $\{e f t\}$ history, current and past. Similarly, the time path of the $\{e f t\}$ sequence is affected by current and past events of the $\{g t\}$ sequence. The VAR of order I(1) is given as:

$$
\begin{aligned}
g_{t} & =a_{10}+a_{11} g_{t-n}+a_{12} e f_{t-n}+e_{g t}, \\
e f_{t} & =a_{20}+a_{21} g_{t-n}+a_{22} e f_{t-n}+e_{e f t},
\end{aligned}
$$

where $g_{t}$ is annual economic growth rate 1995 to $2016(\%), e f_{t}$ is economic freedom index 1995 to 2016 and $n$ is the number of lags. Luetkepohl (2011) argues that traditionally VAR models are constructed for stationary variables without time trends. Since the variables are non-stationary in level format, the I(1) variables were used.

It is assumed that $g_{t}$ and eft are stationary; $e g_{t}$ and $e_{e f t}$ are white-noise disturbances with standard deviations of $\sigma g$ and $\sigma e f$ respectively; and the error terms are uncorrelated. The amount of lag in the VAR model is determined from the information criteria recommended by the final prediction error (FPE), Aike information criterion (AIC), Schwarz criterion (sc) or Hannan-Quinn (HQ). The system incorporates feedback in its structure since gt and eft are allowed to affect each other. The estimated results of the VAR estimation are given in table 6 .

The research results given in table 6 together with the results given in table 5 implies that economic growth is affected by economic freedom using the three different Indices of Economic Freedom; the Heritage Foundation, Fraser Institute and the Freedom House. In the case of the Economic Freedom Index the inverse relationship is to be expected since 1 indicates the highest level of freedom while 7 is the lowest. This is in line with the findings of Panahi, Assadzadeh and Refaei (2014), Wu- 
TABLE 6 VAR Result Estimations Using the Three Measures of Economic Freedom: GDP Growth (integrated in order 1)

\begin{tabular}{|c|c|c|c|c|c|c|}
\hline \multirow{2}{*}{$\begin{array}{l}d(\mathrm{GDP}), d(\mathrm{IEF}), \\
d(\mathrm{EFW}), d(\mathrm{FWI})\end{array}$} & \multicolumn{2}{|c|}{ IEF (4 lags) } & \multicolumn{2}{|c|}{ EFW (4 lags) } & \multicolumn{2}{|c|}{ FWI (4 lags) } \\
\hline & $\mathrm{C}$ & $t$ & $\mathrm{C}$ & $t$ & $\mathrm{C}$ & $t$ \\
\hline Economic growth $(-1)$ & $-0.53^{*}$ & -2.92 & -0.39 & -0.99 & $-0.42^{*}$ & -2.67 \\
\hline Economic growth $(-2)$ & $-0.34^{*}$ & -2.15 & -0.44 & -1.19 & $-0.39^{*}$ & -2.59 \\
\hline Economic growth $(-3)$ & -0.21 & -1.15 & -0.25 & -0.65 & & \\
\hline Economic growth $(-4)$ & 0.03 & 0.12 & -0.27 & -0.77 & & \\
\hline Economic freedom $(-1)$ & 0.05 & 0.16 & 1.94 & 1.03 & -4.84 & -1.87 \\
\hline Economic freedom $(-2)$ & $0.63^{*}$ & 2.37 & 0.56 & 0.02 & $-11.89^{*}$ & -4.51 \\
\hline Economic freedom $(-3)$ & 0.36 & 1.20 & 1.54 & 0.75 & & \\
\hline Economic freedom $(-4)$ & $1.27^{*}$ & 5.02 & 1.04 & 0.53 & & \\
\hline$R$-squared & 0.70 & & -0.21 & & 0.59 & \\
\hline$F$-statistic & 5.66 & & 0.65 & & $7 \cdot 51$ & \\
\hline Sum squared residuals & 8.91 & & 36.05 & & 21.42 & \\
\hline
\end{tabular}

NOTES $\mathrm{C}$-coefficient, $t-t$-statistics. ${ }^{\star}$ Statistically significant $(p<0.05)$. Authors' own analysis using data from Statistics South Africa, the Heritage Foundation, Fraser Institute and the Freedom House.

landari (2015), Justesen (2006), Gurgul and Lach (2011) among others as discussed in the third section.

The result suggest that, in general, overall economic freedom seems to cause or at least be conducive for economic growth, i.e., periods with higher levels of economic freedom leads to higher economic growth rates. The causality is also from economic freedom in the direction of economic growth, and not the other way around as some studies have found. It is therefore possible to argue that part of the economic decline post 2016 is due to the fall in the overall economic freedom levels in South Africa.

The results also indicate that economic freedom causes or supports economic growth only after two to four years. There is therefore a time delay (lagged relationship) between higher (lower) levels of economic freedom and economic progress (decline).

The empirical results of the current study confirms Ajide and Eregha (2015) who found that economic freedom is a key driver supporting economic growth. South Africa should therefore focus on the individual components of overall economic freedom in order to achieve higher levels of economic freedom to support economic growth. The focus should be on 'more' economic freedom and not 'less' economic freedom. 


\section{Conclusions}

Numerous studies suggest that economic freedom is important in promoting economic growth. The current study tested this relationship empirically and the empirical results confirmed that increasing levels of economic freedom causes or supports higher levels of economic prosperity.

This paper studied the relationships between economic freedom and economic growth in South Africa drawing from various empirical studies. Using regression and vector auto regression techniques, the impact of economic freedom on economic growth in South Africa, over the period 1995 to 2016, was investigated in this study.

The economic freedom index in this study was not decomposed in into the various categories however. The total levels of economic freedom produced by the Heritage Foundation, the Fraser Institute and Freedom House were used. The research findings suggested that a significant and positive relationship exit between the level of economic progress in South Africa and the country's economic growth rate. When the levels of freedom decreased, growth declined.

The results therefore provide a solid basis to claim that improvement in economic freedom is a prerequisite of growth. Economic freedom therefore needs to be recognised as potentially important for economic growth. South Africa should therefore put economic freedom on its growth agenda and not ignore it. To support economic growth South Africa should undertake economic freedom reforms in general.

In further research on this topic, an effort should be made to investigate the defining of economic freedom in more detail and providing the study field with a more rigorous theoretical framework on which the study could be based. Some of our empirical results also indicated some negative connections between the two variables and this deserves special attention in further research. The distinction between politics, institutions and economic role-players, and which institutions enhance economic freedom most, also deserve special attention.

\section{References}

Ajide, K. B., and P. B. Eregha. 2015. 'Foreign Direct Investment, Economic Freedom and Economic Performance in Sub-Saharan Africa.' Managing Global Transitions 13 (1): 43-58.

Barzel, Y. 2000. 'Property Rights and the Evolution of the State.' Economics of Governance 1 (1): 25-51.

Bastiat, F. 1850. The Law. New York. 
Carlson, F., and S. Lundström. 2002. 'Economic Freedom and Growth: Decomposing the Effects.' Public Choice 112 (3-4): 335-44.

Dutz, M. A., and A. Hayri, A. 200o. 'Does More Intense Competition Lead to Higher Growth?’ Policy Research Working Paper 2320, World Bank, Washington, DC.

Garrett, T. A., R. M. and Rhine. 2010 'Economic Freedom and Employment Growth in Us States.' Working Paper 2010-006 A, Federal Reserve Bank of St. Louis, Mo.

Gorlach, V. I., and P. Le Roux. 2013. 'The Impact of Economic Freedom on Economic Growth in the s A DC: An Individual Component Analysis.' E Rs A Working Paper 327, ER S A, Cape Town.

Granger, C. W. J., and L. L. Huang. 1997. 'Evaluation of Panel Data Models: Some Suggestions from Time Series.' Discussion Paper 97-10, Department of Economics, University of California, San Diego.

Gurgul, H., and Ł. Lach. 2012. 'The Nexus between Improvements in Economic Freedom and Growth: Evidence from CEE Countries in Transition.' Central European Journal of Economic Modelling and Econometrics 3:133-68.

Gwartney, J. G., and R. A. Lawson. 2002. Economic Freedom of the World: 2002 Annual Report. Vancouver: Fraser Institute.

Gwartney, J., R. Lawson, and J. Hall. 2015. Economic Freedom of the World: 2015 Annual Report. Vancouver: Fraser Institute.

Hayek, F. A. 1960. The Constitution of Liberty. Chicago: University of Chicago Press.

Holcombe, R. G. 1998. 'Entrepreneurship and Economic Growth.' Quarterly Journal of Austrian Economics 1 (2): 45-62.

- 2003a. 'Information, Entrepreneurship, and Economic Progress.' In Austrian Economics and Entrepreneurial Studies, edited by R. Koppl, 173-95. Oxford: Elsevier Science.

- 2003b. 'Progress and Entrepreneurship.' Quarterly Journal of Austrian Economics 6 (3): 3-26.

Kapás, J. and P. Czeglédi. 2007. 'Economic Freedom: A Hayekian Conceptualisation.' New Perspective Political Economy 3:205-30.

Kreft, S. F., and R. S. Sobel. 2005. 'Public Policy, Entrepreneurship, and Economic Freedom.' Cato Journal 25(3): 595-616.

Justesen, M. K. 2006. 'The Effect of Economic Freedom on Growth: Evidence on Causality from a Panel of Countries 1970-2000.' Paper presented at the annual meeting of The European Public Choice Society 2006, Turku, 20-23 April.

Lee, H. S. 1992. 'Maximum Likelihood Inference on Cointegration and Seasonal Cointegration.' Journal of Econometrics 54 (1): 1-47. 
Luetkepohl, H. 2011. 'Vector Autoregressive Models.' E U I Working Papers ECO 2011/30, European University Institute, Fiesole.

Ovaska, T., and R. S. Sobel. 2005. 'Entrepreneurship in Post-Socialist Economies.' Journal of Private Enterprise 21 (1): 8-28.

Panahi, H., A. Assadzadeh, and R. Refaei. 2014. 'Economic Freedom and Economic Growth in Mena Countries.' Asian Economic and Financial Review 4(1): 105-16.

Puddington, A., and T. Roylance. 2016. Freedom in the World 2016. Washington: Freedom House.

Sims, C. A. 1980. 'Macroeconomics and Reality.' Econometrica 48 (1): 1-48. Smith, A. 1986. The Wealth of Nations. London: Penguin.

Voigt, S. 1998. 'Making Constitutions Work: Conditions for Maintaining the Rule of Law.' Cato Journal 18 (2): 191-208.

Wulandari, D. 2015. 'Analysis of the Connection between Economic Freedom and Economic Growth in Indonesia.' Interdisciplinary Journal of Contemporary Research in Business 6 (10): 63-75.

This paper is published under the terms of the Attribution-

NonCommercial-NoDerivatives 4.o International (CC B Y-NC-ND 4.0)

License (http://creativecommons.org/licenses/by-nc-nd/4.o/). 